\title{
High temperature low cycle fatigue characterization of equiaxed MAR-M-247
}

DOI:

10.1016/j.jfatigue.2019.02.021

\section{Document Version}

Accepted author manuscript

Link to publication record in Manchester Research Explorer

\section{Citation for published version (APA):}

Maggiani, G., Roy, M., \& Withers, P. (2019). High temperature low cycle fatigue characterization of equiaxed MARM-247. International Journal of Fatigue, 123, 225-237. https://doi.org/10.1016/j.ijfatigue.2019.02.021

\section{Published in:}

International Journal of Fatigue

\section{Citing this paper}

Please note that where the full-text provided on Manchester Research Explorer is the Author Accepted Manuscript or Proof version this may differ from the final Published version. If citing, it is advised that you check and use the publisher's definitive version.

\section{General rights}

Copyright and moral rights for the publications made accessible in the Research Explorer are retained by the authors and/or other copyright owners and it is a condition of accessing publications that users recognise and abide by the legal requirements associated with these rights.

\section{Takedown policy}

If you believe that this document breaches copyright please refer to the University of Manchester's Takedown Procedures [http://man.ac.uk/04Y6Bo] or contact uml.scholarlycommunications@manchester.ac.uk providing relevant details, so we can investigate your claim.

\section{OPEN ACCESS}




\title{
High temperature low cycle fatigue characterization of equiaxed MAR-M-247
}

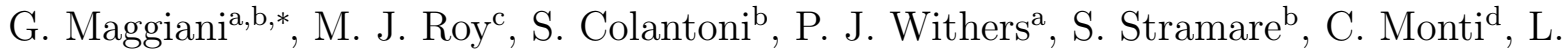 \\ Bernardini $^{\mathrm{d}}$ \\ ${ }^{a}$ School of Materials, The University of Manchester, Manchester, UK, M13 9PL \\ ${ }^{b}$ Baker Hughes, a GE Company, Via Felice Matteucci, 2 - Florence, 50127 Italy \\ ${ }^{c}$ School of Mechanical, Aerospace and Civil Engineering, The University of Manchester, Manchester, UK, \\ M13 $9 P L$ \\ ${ }^{d}$ Pontlab S.r.l. Via Lazio, 4 - Zona Industriale Gello - Pontedera 56025 (Pi), Italy
}

\begin{abstract}
Low cycle fatigue tests have been performed at $1038^{\circ} \mathrm{C}$ on equiaxed MAR-M-247 under a mean compressive strain. Strain ranges assessed were $0.4,0.6$ and $0.8 \%$, with this test program reflecting industrial gas turbine duty cycles. Fractographic analysis demonstrated transgranular crack propagation with intergranular fast fracture. Heavily oxidized secondary cracks were observed throughout. The details of a Lemaitre-Chaboche constitutive model that has been applied to the experimental stress-strain response are described. It was found that this model was capable of capturing both plastic shakedown and kinematic hardening effects with a high degree of accuracy ( $\mathrm{R}^{2}$ up to 0.997 and SSE up to $\left.6 \mathrm{E}+4\right)$. The suitability of extending this model to address different strain histories are detailed.
\end{abstract}

Keywords: MAR-M-247, Low Cycle Fatigue, Lemaitre-Chaboche, Fracture

\section{Nomenclature}

$\alpha \quad$ Instantaneous deviatoric backstress $\quad$ MPa

$\Delta \sigma \quad$ Stress range variation $\quad \mathrm{MPa}$

$\Delta \varepsilon \quad$ Strain range variation

\footnotetext{
*Corresponding author, Tel. +39 055458 4479; Fax +39 0554232893

Email addresses: gianluca.maggiani@bhge.com (G. Maggiani),

matthew.roy@manchester.ac.uk (M. J. Roy), simone.colantoni@bhge.com (S. Colantoni),

p.j.withers@manchester.ac.uk (P. J. Withers), stefania.stramare@bhge.com (S. Stramare), cosimo.monti@bhge.com (C. Monti), luca.bernardini@bhge.com (L. Bernardini)
} 
$5 \hat{\varepsilon} \quad$ Accumulated plastic strain in viscoplastic model

$\sigma \quad$ Invariant component of the stress tensor $\quad \mathrm{MPa}$

$\begin{array}{lll}\sigma_{\mathrm{D} \infty} & \text { Saturated drag stress } & \mathrm{MPa}\end{array}$

$\sigma_{\mathrm{D}} \quad$ Drag stress, describing the size of the yield surface $\quad$ MPa

$\begin{array}{lll}\sigma_{\max } & \text { Maximum stress } & \mathrm{MPa}\end{array}$

${ }_{10} \sigma_{\min }$ Minimum stress $\quad \mathrm{MPa}$

$\begin{array}{lll}\sigma_{\mathrm{r}} & \text { Predicted stress from mathematical algorithm } & \mathrm{MPa}\end{array}$

$\sigma_{\text {test }}$ Experimental stress value $\quad$ MPa

$\sigma_{\mathrm{y}} \quad$ Yield Strength $\quad \mathrm{MPa}$

$\varepsilon \quad$ Total strain

${ }_{15} \quad \varepsilon_{\mathrm{a}} \quad$ Strain amplitude over a loading cycle

$\varepsilon_{\mathrm{e}} \quad$ Elastic strain

$\varepsilon_{\mathrm{m}} \quad$ Mean strain over a loading cycle

$\varepsilon_{\mathrm{p}} \quad$ Plastic strain

$a_{i} \quad$ Kinematic hardening parameter

${ }_{20} \quad b \quad$ Isotropic hardening stabilization parameter in viscoplastic model

$\begin{array}{lll}c_{i} & \text { Kinematic hardening parameter } & \mathrm{MPa}\end{array}$

E Modulus of elasticity $\quad$ GPa

$\begin{array}{lll}J & \text { Plastic strain flow rule free parameter } & \text { MPa }\end{array}$

$m \quad$ Free parameter in the plastic strain flow rule

${ }_{25} \quad$ Number of cycles 
$N_{\mathrm{f}} \quad$ Number of cycles for failure

$N_{\text {in }} \quad$ Number of cycles for crack initiation

$N_{\mathrm{s}} \quad$ Number of cycles for saturation

$Q \quad$ Isotropic hardening variable in viscoplastic model $\quad \mathrm{MPa}$

so $\quad q \quad$ Asymptotic value of the evolution of isotropic hardening

$\mathrm{MPa}$

$X \quad$ Kinematic hardening variable in viscoplastic model

$\mathrm{MPa}$

\section{Introduction}

In gas turbine (GT) applications, one of the primary modes of crack initiation for components that operate at elevated temperatures is low cycle fatigue ( $\mathrm{LCF})$, which is often exacerbated by creep phenomena and environmental material degradation. GT components might be subjected to vibratory loads due to aero-mechanical excitation which leads to high cycle fatigue $(\mathrm{HCF})$ failures. However, $\mathrm{HCF}$ is not the main driver for premature failure of hot gas path components as thermal strains have a much larger impact on crack nucleation. Increased thermal efficiency demands, coupled with the changing environments in which industrial GTs are installed make material selection and LCF life assessment critical for safe and reliable operability. Secondary effects, such as creep under elevated static loads and temperature, in addition to superimposed vibratory loading, also need to be considered when performing fatigue life assessments of hot gas path stator components [1].

Start-up and shut-down cycling of GTs impose LCF conditions that can result in crack initiation. For specific internal components such as nozzles, this may decrease performance, increase repair costs and the risk of a forced outage. Standard characterization methodologies historically use isothermal strain range versus cyclic life data in the calculation of fatigue lives [2]. However, LCF in nozzles is typically produced as a result of thermally driven loading, where the strain range is generated by continuous changes in the component temperature throughout a duty cycle. Thermal stresses are created by temperature variations within a connected structure, where the thermal expansion of hot material is constrained by regions 
of cooler material. The result is a complex stress state that varies throughout an operating regime.

The currently accepted industrial practice of assessing LCF can be done in one of following two ways. The first is an elastic analysis (i.e. linear elastic fracture mechanics) and resolves loads which predict unreasonably long LCF life when compared to experimental results [3]. The second is an elastic-plastic approach, whereby care must be taken to avoid underestimating operating stresses, which can lead to non-conservative prediction of LCF fatigue lives. Overly-simplistic assessment of inelastic phenomena, i.e. linear plastic flow, can lead to further complications. Therefore, there exists the opportunity to improve upon elastic-plastic approaches by applying plasticity models that account for temperature-dependent inelastic response and material anisotropy [4].

Nickel based alloys are specifically used for high temperature applications because of their strength mainly provided by their significant volume fraction of $\gamma^{\prime}$ precipitates. This specific 65 effect is driven by the constraint that is imposed to the $\gamma$ matrix by $\gamma^{\prime}$ precipitates [5, 6]. As a result, all nickel-based polycrystalline superalloys have the ability to retain their strength up to a high fraction of melting temperature. A common alloy employed for GT applications is MAR-M-247, which is able to retain its yield strength up to $\sim 800^{\circ} \mathrm{C}$. This alloy is similar to a more commonly specified alloy known commercially as Rene 108, but contains additional alloying elements to improve castability and creep resistance. Table 1 summarizes the typical chemical composition of MAR-M-247.

Table 1: Typical chemical composition of MAR-M-247

\begin{tabular}{|c|c|c|c|c|c|c|c|c|c|c|c|c|}
\hline $\begin{array}{l}\text { Alloying } \\
\text { element }\end{array}$ & Co & $\mathrm{W}$ & $\mathrm{Cr}$ & $\mathrm{Al}$ & $\mathrm{Ta}$ & $\mathrm{Hf}$ & $\mathrm{Ti}$ & Mo & $\mathrm{C}$ & $\mathrm{Zr}$ & B & $\mathrm{Ni}$ \\
\hline \multicolumn{13}{|l|}{ Weight } \\
\hline $\begin{array}{l}\text { Fraction } \\
\text { (\% wt.) }\end{array}$ & $9.15-10.15$ & $9.5-10$ & $8.2-8.8$ & $5-6$ & 2.9-3.4 & $1.2-1.8$ & $<1.0$ & $<1$ & $<0.1$ & $<0.2$ & $<0.2$ & Bal. \\
\hline
\end{tabular}

Constitutive modeling the response of MAR-M-247 to thermally-assisted LCF conditions 
indicative of GT operating regimes has been documented previously. Brindley [7] studied the application of the Sehitoglu-Boismier unified thermo-viscoplasticity constitutive model up to $1038^{\circ} \mathrm{C}$, showing its capability of assessing the stable stress-strain response for fully-reversed cycling. The mechanical strain ranges considered in his study were one for $980^{\circ} \mathrm{C}(\Delta \varepsilon=$ $0.8 \%)$ and two for $1038^{\circ} \mathrm{C}(\Delta \varepsilon=0.7$ and $0.8 \%)$. The material analyzed had a large grain size (between 2 and $7 \mathrm{~mm}$ ), which is surmised to be because of a low initial cooling rate. Both Halford [2] and Kaufman [8] in their respective studies highlighted the large effect that different strain ranges $(\Delta \varepsilon=0.5,0.58,0.67,078$ and $0.90 \%)$. Kaufman [8] performed different $\mathrm{LCF}$ tests at various strain ranges focusing on three temperatures $\left(200,420\right.$ and $\left.760^{\circ} \mathrm{C}\right)$. The grain size Kaufman considered had a maximum size of about $3 \mathrm{~mm}$, and based on similarities in mechanical response, the same size is assumed for Halford. Martin-Meizoso [9] provided an semi-empirical formulations and physical models. LCF thermomechanical fatigue tests were performed both in and out of phase loading as well as with dwell time at temperature on material with an average grain size of $1.5 \mathrm{~mm}$. Both Martin-Meizoso and Brindley focused on symmetric fatigue cycles with $\varepsilon_{\mathrm{m}}=0$ and mechanical strain ranges from 0.2 up to $0.4 \% \Delta \varepsilon$.

The present work documents the LCF response of MAR-M-247 at a higher temperature and larger strain ranges than previously reported in the literature, on material with a smaller grain size. Cyclic conditions where $\varepsilon_{\mathrm{m}}=-\varepsilon_{\mathrm{a}}$ have been evaluated, reflecting conditions imposed on a GT nozzle. Crack initiation and fractographic analysis of LCF specimens will be presented, and the mechanical response will be analyzed within a Lemaitre-Chaboche and lead to more reliable life assessment predictions for other components made from this type of high temperature superalloy.

\section{Material and experimental conditions}

All material in the present work was vacuum investment-cast and then heat treated with 100 solid solution and ageing, as per Fig. 11(a). This resulted in an optimized microstructure consisting of a $\gamma$ matrix strengthened by cubic $\gamma^{\prime}$ precipitates. The casting and heat treatment 
procedures produced a nominal equiaxed microstructure as shown in Fig. 1(b) and in Fig. 1 (c), with a mean grain size of approximately $500 \mu \mathrm{m}$. Kashinga et al. [12] demonstrated a strong anisotropic behavior of MAR-M-247 directionally solidified in fatigue life, which is both strain rate and orientation dependent. This means that the results of this present study may not be directly applicable to anisotropic (i.e. directionally solidified) MAR-M-247. The ageing procedure enabled precipitation of the $\gamma^{\prime}$ phase up to approximately $60 \%$ by volume, optimal for peak mechanical properties [5]. Other key observable features include grain boundary carbides, which provide additional strengthening by suppressing grain boundary sliding at elevated temperatures [7]. Additionally, coarse primary carbides (white features) which play an important role in fracture as the initiation site of cracks on MC- $\gamma$ interfaces [14. The main difference in the material employed in the present versus other studies is the grain size, which has been brought about by different casting procedures and composition (e.g. C and W). Fig. 1(d) and (e) show the evolution of the microstructure when subjected 115 to cyclic loading at high temperature. It is clear that the precipitates coarsen from the heat treated condition (Fig.1 (d)), to assume a more globular rounded morphology (Fig.1 (e)), after the material has been exposed to $1038^{\circ} \mathrm{C}$ for one hour and twenty minutes after a cyclic LCF test.

LCF testing in the present work was carried out adhering to the ASTM E606-12 stan120 dard under strain control, under mean compressive strain (e.g. $A=-1)$ conditions. An MTS 312.21 frame with a 793 controller and 632.53 extensometer was employed to do so. The specimens were machined in accordance to the ASTM E606-12 standard specifications, each having a gauge length of $19 \mathrm{~mm}$ and a nominal gauge section diameter of $5 \mathrm{~mm}$ as per Fig. 2. The specimens were heated using a $2.4 \mathrm{~kW}$ induction heater and the temperature tions were employed to reflect operating conditions of turbine components. Specimens were temperature soaked at the reference temperature for at least one hour prior to deformation. A triangular cyclic waveform was employed with a $0.5 \mathrm{~Hz}$ frequency for all specimens. The test termination criterion imposed was either specimen fracture or a load drop of $50 \%$ as ascertained from the stabilized response in accordance with Section 8.9.4 of ASTM E606-12. 


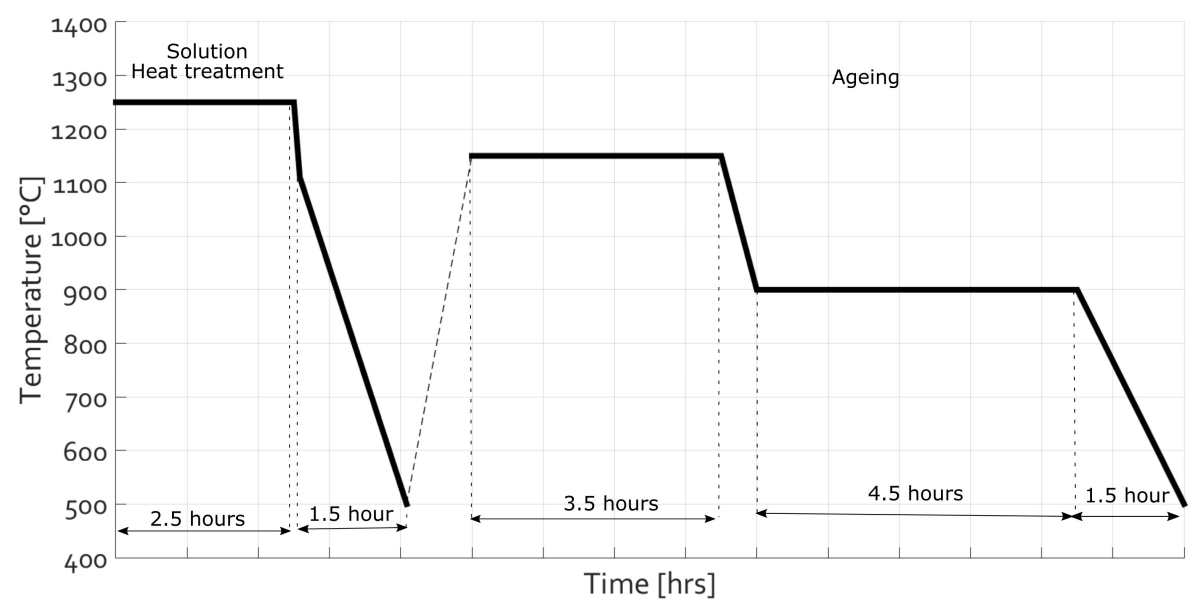

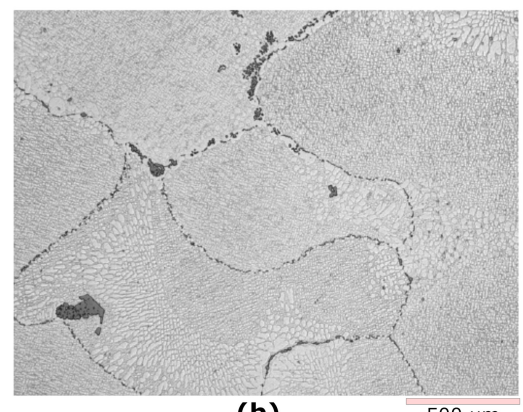

(b)

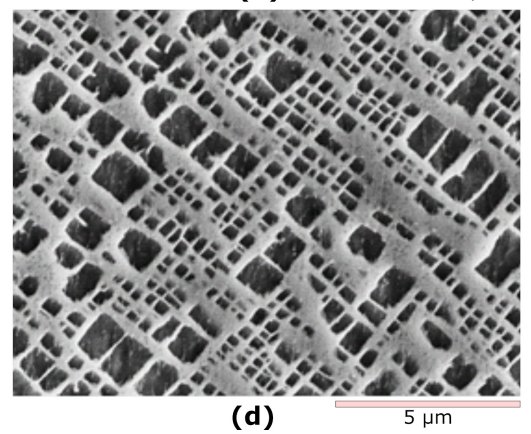

(a)
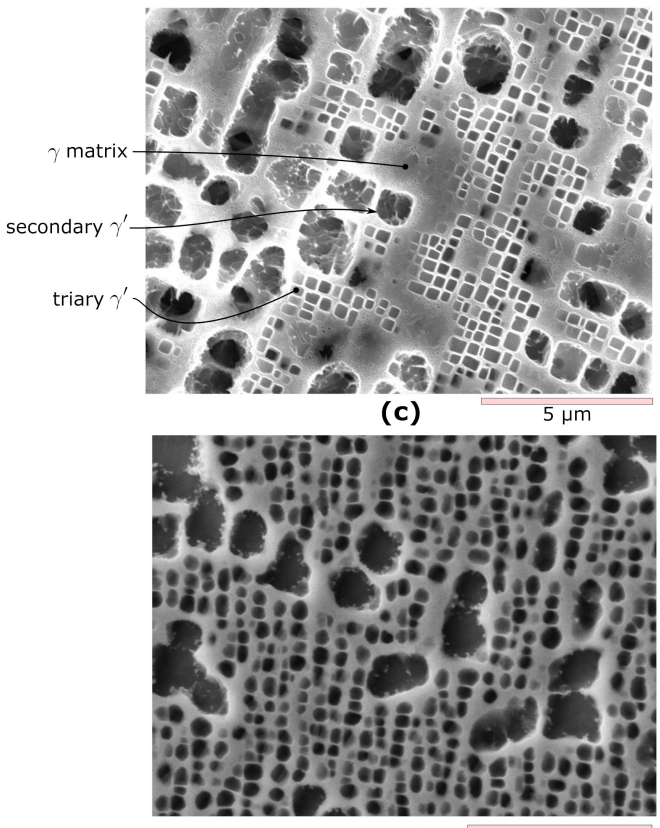

(e)

Figure 1: Heat treatment and typical MAR-M-247 microstructure before and after exposure to elevated temperature. Solution heat treatment and ageing scheme employed (a) and a secondary electron SEM image showing typical grain size (b). Secondary electron SEM image of the $\gamma$ matrix that can be seen with embedded coherent $\gamma^{\prime}$ precipitates (c). These precipitates coarsen from the heat-treated condition (d) to assume a more globular morphology. This is readily apparent in (e) which shows the microstructure for specimen $5\left(1038^{\circ} \mathrm{C}\right.$ with $\left.\Delta \varepsilon=0.4 \%, \mathrm{~N}_{s}=335, \mathrm{~N}_{i n}=1532, \mathrm{~N}_{f}=2379\right)$. 


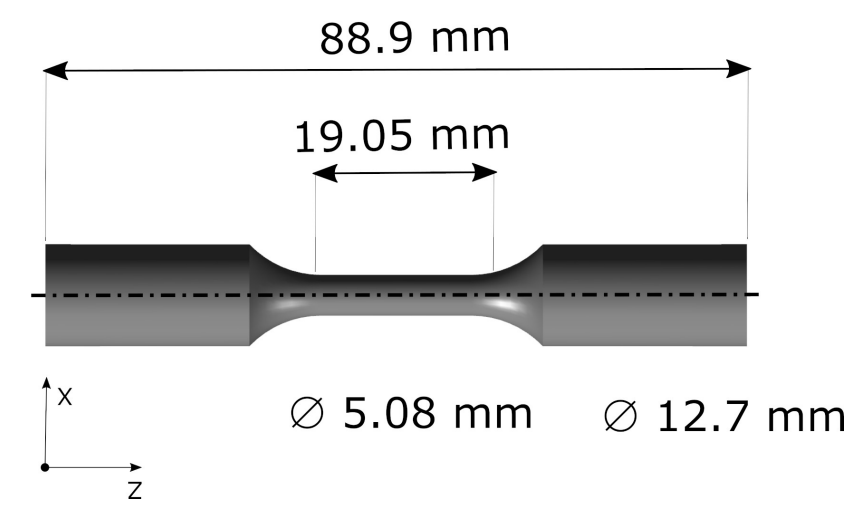

Figure 2: Specimen geometry and orientation.

\section{Experimental results}

Statistical analysis of experimental data from the 6 tests performed shows a good agreement between the test results and the literature data for this material [2, 8, 9]. This can be highlighted for example by comparing the Young's modulus, see Fig. 3. The hardening behavior can be highlighted by comparing the maximum stress $\left(\sigma_{\max }\right)$ attained at the first cycle and at midlife. The midlife is defined as the cycle just falling in between end of life and the beginning of the stabilized cycles. The minimum stress attained $\left(\sigma_{\min }\right)$ is seen to decrease at a different rate, which demonstrates that there are two non-linear effects which need to be considered, kinematic hardening and plastic shakedown; phenomena which this material has been noted to exhibit previously [15]. Table 2 summarizes the data collected at $1038^{\circ} \mathrm{C}$ for each specimen tested. Crack initiation detection was accomplished by means of a continuous load monitor and represents a discernible deviation from the mean after the stabilized portion of the test record. It is evident from Table 2 that specimen 2 displayed aberrant behavior, and is not included in subsequent constitutive behavior development.

The fracture surfaces were examined by optical microscope (Leica M205AE) and scanning electron microscope (Zeiss Supra 55).

Examination of fracture surface initiation sites revealed that most sites coincided with the presence of incoherent hafnium carbides. It is surmised that either cracks initiated at these carbides, or their presence near to the surface accelerated crack growth. The crack surfaces appeared to differ according to the local distribution of precipitate and incoherent hafnium carbides. Although the fracture surfaces have been somewhat compromised by oxidation, 


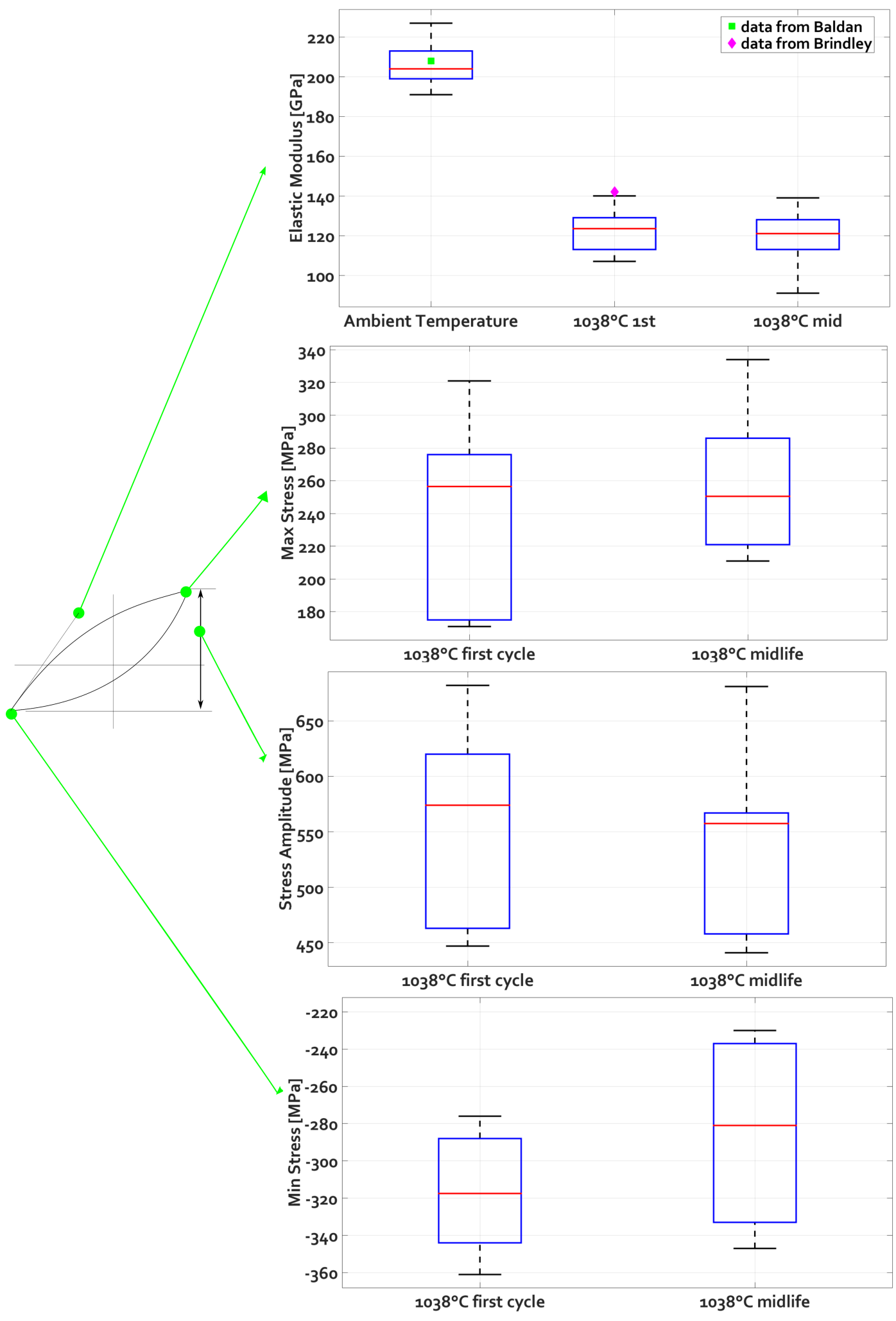

Figure 3: Variation in elastic modulus and load carrying capacity with respect to temperature. The bottom and top edges of the box indicate the $25^{\text {th }}$ and $75^{\text {th }}$ percentiles, respectively. The bars extend to the most extreme data points that are not considered outliers. Literature data for the modulus are taken from Brindley 7] and Baldan et al. [16]. 
Table 2: Test result summary

\begin{tabular}{|c|c|c|c|c|c|c|c|c|c|c|c|c|}
\hline \multirow[b]{2}{*}{$\begin{array}{l}\text { Specimen } \\
\text { Id. }\end{array}$} & \multirow[b]{2}{*}{$\begin{array}{l}\Delta \epsilon \\
(\%)\end{array}$} & \multirow[b]{2}{*}{$\begin{array}{c}\mathrm{E} \\
(\mathrm{GPa})\end{array}$} & \multicolumn{3}{|c|}{ First Cycle } & \multirow[b]{2}{*}{$\begin{array}{c}\mathrm{E} \\
(\mathrm{GPa})\end{array}$} & \multicolumn{2}{|c|}{ Mid Life } & \multirow[b]{2}{*}{$\begin{array}{c}\Delta \sigma \\
(\mathrm{MPa})\end{array}$} & \multirow[b]{2}{*}{$\mathrm{N}_{\mathrm{s}}$} & \multirow[b]{2}{*}{$\mathrm{N}_{\text {in }}$} & \multirow[b]{2}{*}{$\mathrm{N}_{\mathrm{f}}$} \\
\hline & & & $\begin{array}{c}\sigma_{\max } \\
(\mathrm{MPa})\end{array}$ & $\begin{array}{c}\sigma_{\min } \\
(\mathrm{MPa})\end{array}$ & $\begin{array}{c}\Delta \sigma \\
(\mathrm{MPa})\end{array}$ & & $\begin{array}{c}\sigma_{\max } \\
(\mathrm{MPa})\end{array}$ & $\begin{array}{c}\sigma_{\min } \\
(\mathrm{MPa})\end{array}$ & & & & \\
\hline 1 & 0.8 & 129 & 321 & -361 & 682 & 128 & 334 & -347 & 681 & 43 & 226 & 308 \\
\hline 2 & 0.8 & 107 & 276 & -344 & 620 & 91 & 223 & -333 & 556 & - & 21 & 31 \\
\hline 3 & 0.6 & 124 & 263 & -314 & 577 & 121 & 286 & -281 & 567 & 58 & 502 & 1027 \\
\hline 4 & 0.6 & 113 & 250 & -321 & 571 & 113 & 278 & -281 & 558 & 95 & 537 & 947 \\
\hline 5 & 0.4 & 140 & 175 & -288 & 463 & 139 & 221 & -237 & 458 & 335 & 1532 & 2379 \\
\hline 6 & 0.4 & 123 & 171 & -276 & 447 & 121 & 211 & -230 & 441 & 439 & 3215 & 3581 \\
\hline
\end{tabular}

only the interfaces between the primary $\gamma$ phase and hafnium carbides have been separated by crack propagation, as highlighted by the intervals between the crack changing direction. Furthermore, the interval between striations not encompassing hafnium carbides approaches that of the precipitates' length scale, the order of $10 \mu \mathrm{m}$ - much less than the grain size.All the specimens tested showed a transgranular crack propagation with intergranular fast fracture behavior. Furthermore, most of the specimens demonstrated transgranular secondary cracks. Only specimen 2 did not demonstrate any secondary cracking, which has been attributed to the presence of voids/casting porosity as highlighted in Fig. 4.

Cracks predominantly propagate on a transgranular basis (Fig. 5(e)) up to final rupture, which appears to be intergranular as per Fig. 5 (c). Bright features appearing in Fig. 6 (a) are hafnium carbides that fracture surfaces tend to originate from, Fig. 6 (b) . On the fracture surface, it is possible to highlight two different zones (Fig. 5 (b), (d) and (e)). One shows oxidation and a typical transgranular surface with fatigue striations. The other one 165 is intergranular, and a lack of oxidation is evident. The former is indicative the initiation and propagation phase, while the latter is final fracture. There is evidence of secondary transgranular cracks which have heavily oxidized.

Contrary to fracture mechanisms observed for most specimens, specimen 2 does not show any signs of crack propagation (Fig. 4). The fracture surface is quite irregular due to 170 fast fracture and shows a interdendritic crack path. Based on microscopy, the presence of 

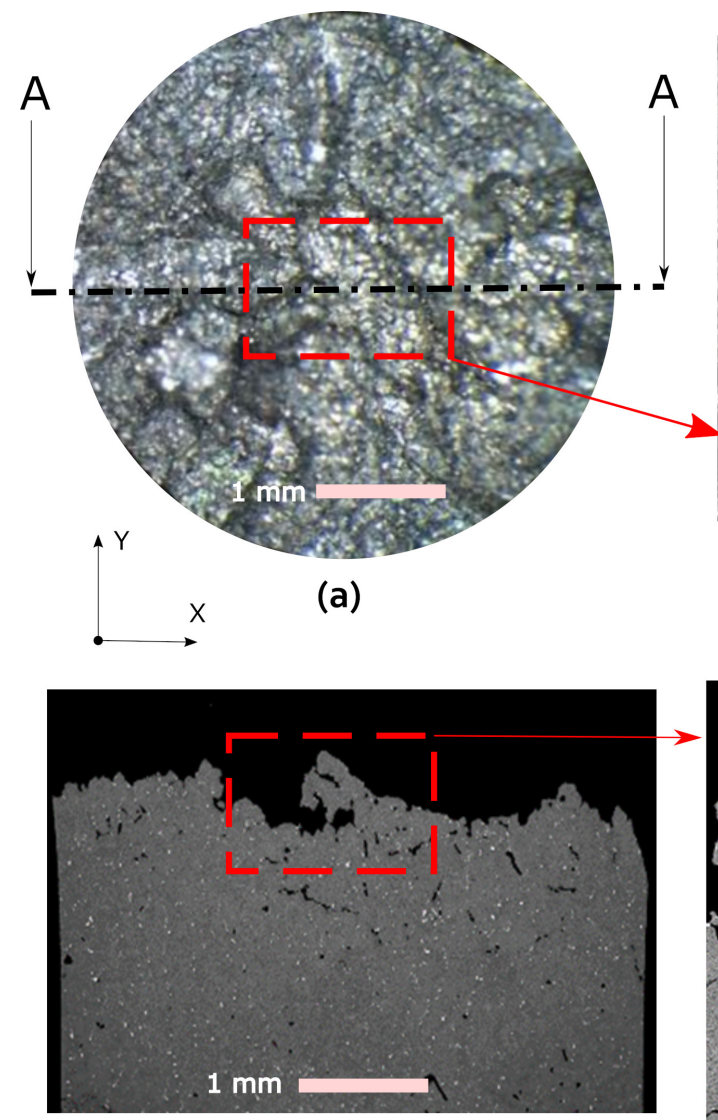

section $A-A$

(c)

$\wedge \mathrm{Z}$

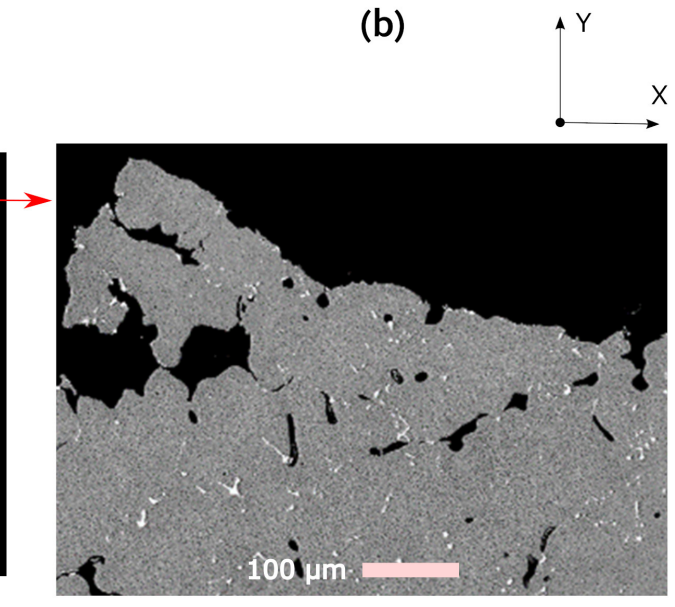

(d)

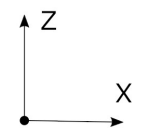

Figure 4: Specimen 2 fracture surface $\left(1038^{\circ} \mathrm{C}, \Delta \varepsilon=0.8 \%, \mathrm{~N}_{\mathrm{in}}=21, \mathrm{~N}_{\mathrm{f}}=31\right)$. Optical image of fracture surface (a). Optical micrography of the fracture surface at higher magnification showing dendritic features (b). Secondary electron SEM image of large voids that are found immediately below the fracture surface (c - d). 


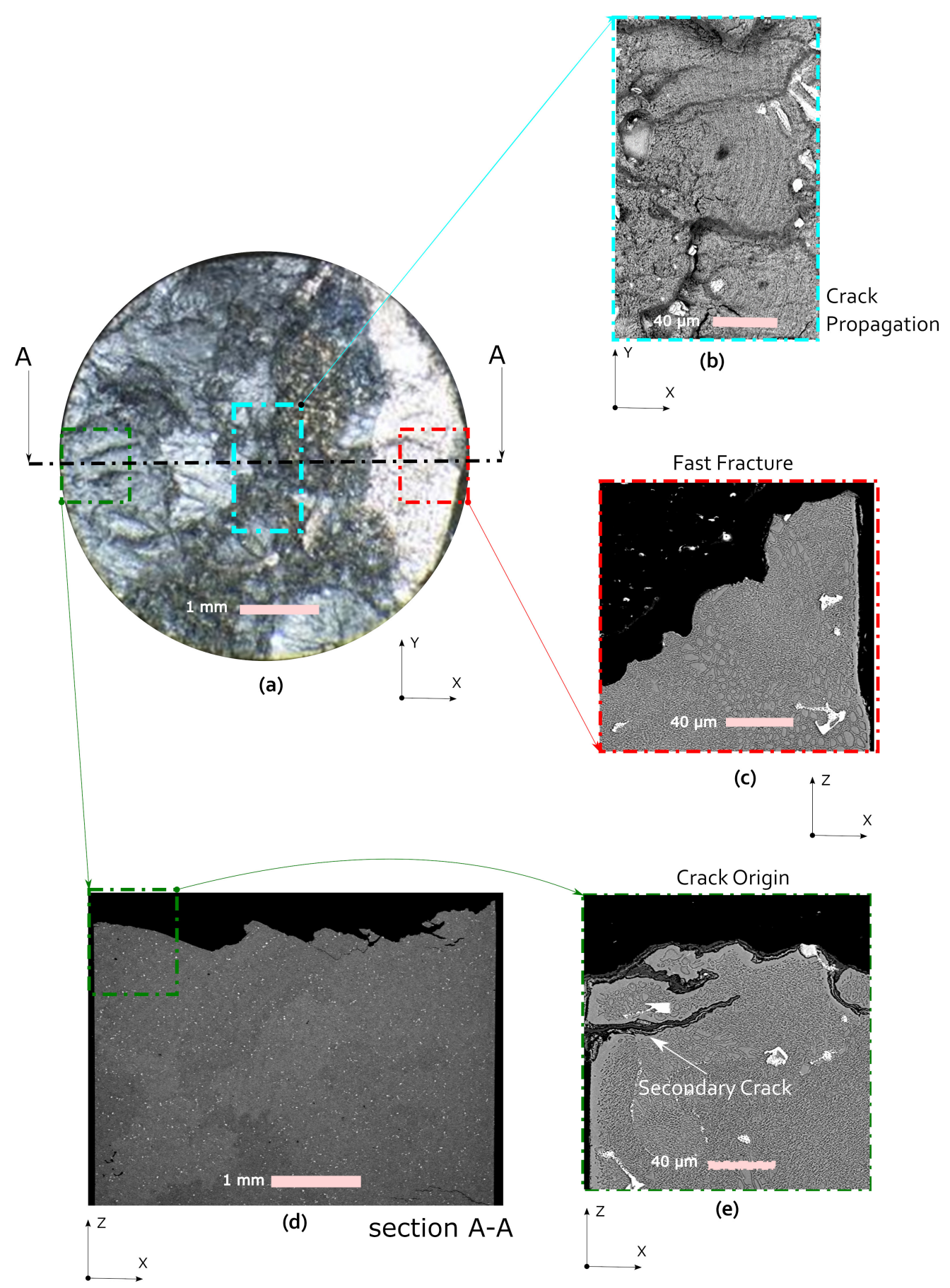

Figure 5: Characteristic response to fatigue initiation and propagation as demonstrated by Specimen 6 $\left(1038^{\circ} \mathrm{C}, \Delta \varepsilon=0.4 \%, \mathrm{~N}_{\mathrm{s}}=439, \mathrm{~N}_{\mathrm{in}}=3215, \mathrm{~N}_{\mathrm{f}}=3581\right)$. OM image showing a typical fracture surface depicting crack initiation, crack propagation and up to fast fracture (a). Secondary electron SEM image with beachmark striations depicted (b). Detailed view of the fast fracture surface (c). Sectioned fracture surface showing crack initiation, crack propagation up to fast fracture (d). Crack origin along with a secondary crack that did not lead to rupture is shown in detail (e). 


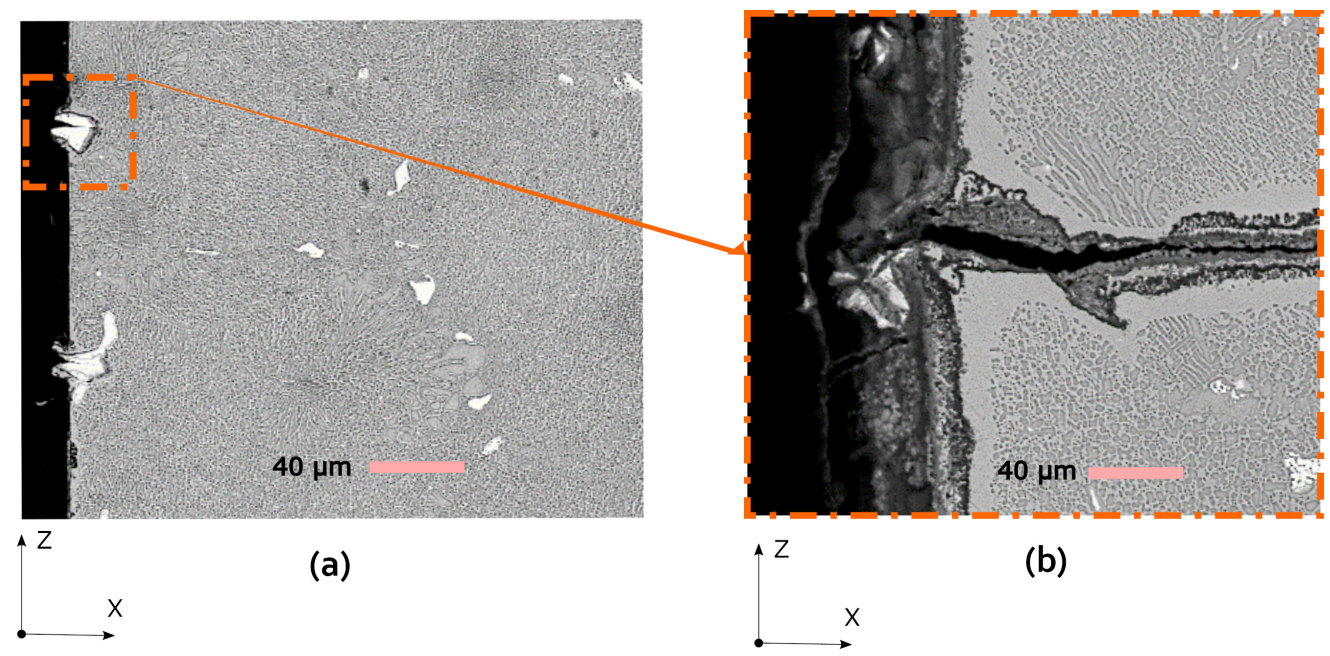

Figure 6: Initiation was found to be predominantly from hafnium carbides (a). The right detail (b) shows the evolution of cracks from hafnium carbides. These are ousted towards the outer surface, creating a defect from which cracks have origin.

voids/pores stemming from the casting process explains why this specimen did not present the same failure modes as the others.

From the stress-strain response, it appears that there was significant hardening and shakedown across all strain ranges. Fig. 7 (a) shows the first versus the stabilized cycle for a representative test from each strain range. Here, the stabilized cycle has been designated as the cycle closest to where the stress ratio versus cycle count first tended to zero. It should be noted that before stabilization, there were cycles having a mean stress close to zero, although the mean strain was compressive. Fig. 7 (b) highlights the hardening that took place before stabilization showing the stress amplitude development as function of number of cycles. Some serrated yielding behavior was also observed where load reversal occurred, which demonstrates a dynamic strain ageing phenomena. This has been previously observed by van den Beukel and Gordon [17, 18].

\section{Viscoplasticity modeling}

The mechanical response recorded has permitted capturing viscoplastic behavior within a mathematical framework. The first step in accomplishing this was to decompose the overall strain $\varepsilon$ into elastic $\left(\varepsilon^{e}\right)$ and inelastic $\left(\varepsilon^{p}\right)$ components. Here, the approach taken reflects that presented by Hart et al. [19]. It should be noted that the viscoelastic behavior observed 


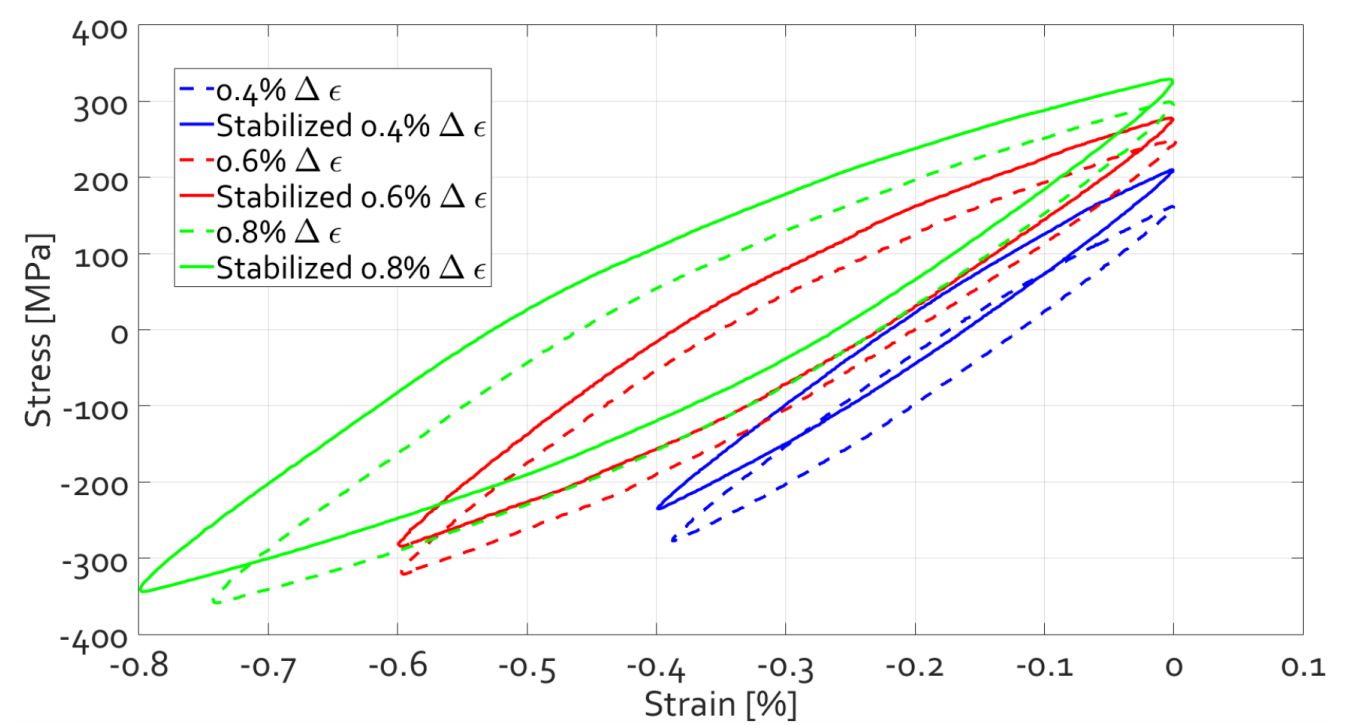

(a)

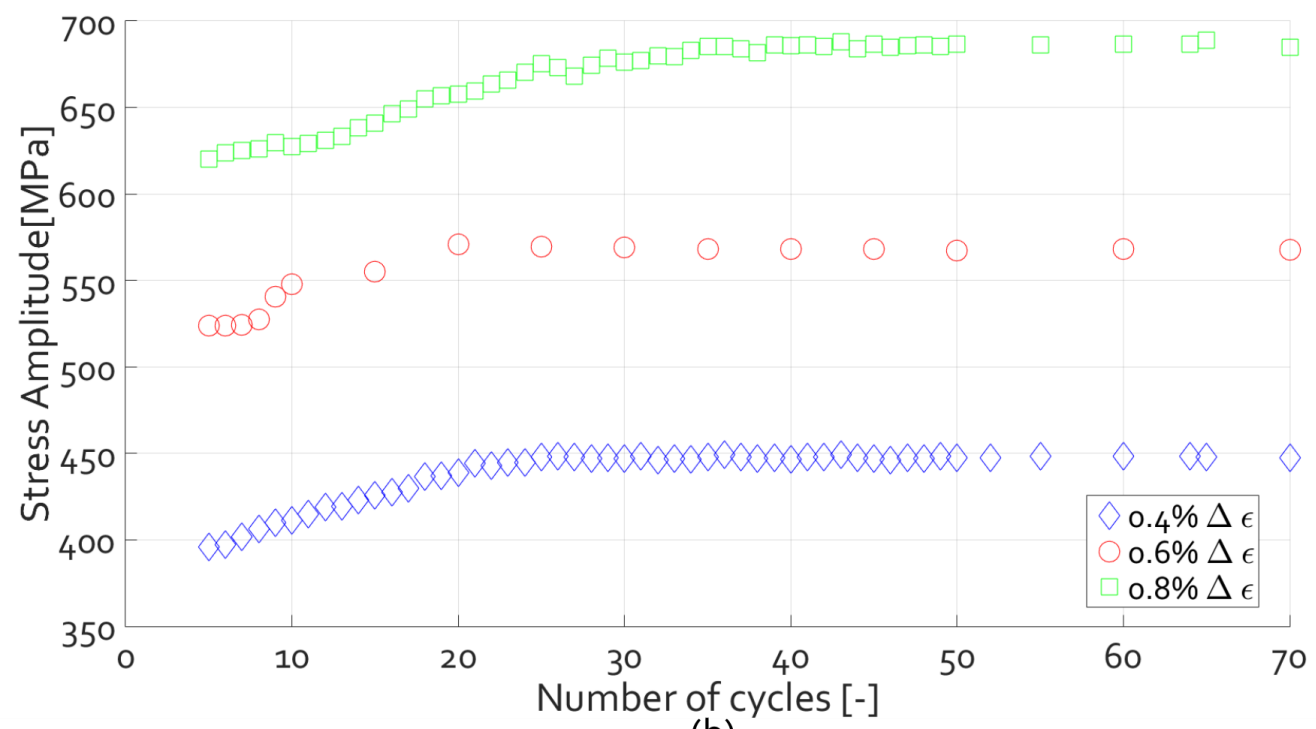

(b)

Figure 7: (a) Initial and stabilized cycles plotted with dashed and solid lines, respectively, for specimens at $1038^{\circ} \mathrm{C}$ and different strain ranges. Hardening effects on material as well as the accumulation of plastic strain is clearly apparent. Specimen 1 tested at $\Delta \varepsilon=0.8 \%$ stabilized after 43 cycles. Specimen 4 tested at $\Delta \varepsilon=0.6 \%$ stabilized after 95 cycles. Specimen 6 tested at $\Delta \varepsilon=0.4 \%$ stabilized after 439 cycles. (b) Stress amplitude progress as function of the number of cycles for the same specimens shown in (a). 
occurred at loads much less than a typical $0.2 \%$ proof or yield stress, particularly in scenarios due to activated creep mechanisms [20].

What follows is a summary of the approach to fit the material response by first describing the overall form of the constitutive behavior, as well as specific aspects of this behavior. This includes linear (elastic) response, isotropic and kinematic hardening as well as optimization approaches.

\subsection{Lemaitre-Chaboche model}

The Lemaitre-Chaboche (LC) [21], 22], 23] has predominantly been employed in nuclear applications but has been extended and applied by others since being first proposed, most notably by Chaboche et al. [24], Tong et al. [25], Zhan et al. [26], Saad [20], Hart et al. [19] and Novak [27]. The main difference between the LC and other widely-used viscoplasticity models such as Neu [28] and Sehitoglu [11], is that LC model does not differentiate plasticity and creep dominant regimes, but uses a unique flow equation. Furthermore, Neu [28] and Sehitoglu [11] do not explicitly capture the elastic domain. As a result, both of these latter formulations imply that inelastic flow starts immediately after the material is loaded.

Employing a formulation to describe inelastic flow, a backstress equation describing the evolution of the yield surface center, and governing equations for yield surface size evolution it has the ability to describe a multitude of thermomechanical effects. Saad, Harth and Novak applied the LC model to steels developing different fitting routines for kinematic and isotropic parameters. The translation of the elastic region (kinematic hardening) is rendered dependent on instantaneous plastic strain, i.e. the strain associated with the stress change within the hysteresis cycle, whereas the increase in yield surface size (isotropic hardening) is rendered dependent on accumulated plastic strain. For virgin material, the center of the elastic domain is initially zero with the limits $\sigma_{\mathrm{y}}$ in tension and $-\sigma_{\mathrm{y}}$ in compression. The function described in Eq. 1 defines the onset of plastic flow by $f>0$ under consideration of hardening effects:

$$
f(\sigma, X, Q)=|\sigma-X|-Q-\sigma_{y}
$$

Here, $X$ describes kinematic while $Q$ describes isotropic hardening, which are superimposed over a description of elastic response. A temperature-dependent strain rate term is included 
plas parameters have been fitted via a Levenberg-Marquardt (LM) optimization methodology implemented in MATLAB!

Table 3: Lemaitre-Chaboche constitutive behaviour formulation.

\begin{aligned} \hline Strain & $\varepsilon(t)=\varepsilon^{e}(t)+\varepsilon^{p}(t) \\$\hline Elasticity & $\sigma(t)=E \varepsilon^{e}(t) \\$\hline Flow Rule & $\dot{\varepsilon}(t)=\left(\frac{1}{J}\left(|\sigma(t)-X(t)|-Q(t)-\sigma_{y}\right)\right)^{m} \operatorname{sgn}(\sigma(t)-X(t)) \\$\hline Hardening & $X(t)=X_{1}(t)+X_{2}(t)+X_{3}(t) \\ & \dot{X}_{i}(t)=c_{i} \dot{\varepsilon}^{p}(t)-a_{i} X_{i}(t)\left|\dot{\varepsilon}^{p}(t)\right| \\ & \dot{Q}(t)=b(q-Q(t))\left|\dot{\varepsilon}^{p}(t)\right| \\$\hline Parameters & $\mathrm{E}, \sigma_{y} \\ & J, m$ (flow Rule) \\ & $a_{1}, a_{2}, a_{3}, c_{1}, c_{2}, c_{3}, b, q$ (hardening) \end{aligned}

\subsection{Linear model formulation}

The first step of the linear model formulation was to define elastic response. Isotropic as well as kinematic hardening effects evolve, so that there is not a unique definition for the elastic modulus and yield for all the strain ranges tested. These values were calculated during tension and compression phases on a per-cycle basis. For all three strain intervals, the parameters for the first cycle were evaluated. This was in addition to the first, saturated,

\footnotetext{
${ }^{1}$ MATLAB is a trademark of The MathWorks Inc., Natick, MA.
} 

for the mathematical model and have been applied in this paper.

A linear fit of the relevant portion of the saturated cycle was performed, as per Fig. 8, Once fit, the threshold for linear - non linear behavior defined the yield point. The elastic modulus as calculated was used to evaluate the error between the model and experimental data. The onset of yielding for the material was considered as the first point in which the difference between test data and model values was greater than 0 , with an increasing difference. This criteria for defining the yield stress given by Eq. 2 .

$$
\sigma_{y}=\left\{\begin{array}{l}
\left|\sigma_{\text {test }}-\sigma_{\mathrm{r}}\right|>0, \\
\frac{\left|\sigma_{\text {test }}-\sigma_{\mathrm{r}}\right|_{\text {cycle } \mathrm{i}+1}-\left|\sigma_{\text {test }}-\sigma_{\mathrm{r}}\right|_{\text {cycle } \mathrm{i}}}{\left|(\Delta \epsilon)_{\text {cycle } \mathrm{i}+1}-(\Delta \epsilon)_{\text {cycle i }}\right|} \neq 0
\end{array}\right.
$$

The adequacy of this approach and subsequently described aspects of the model have been assessed using the coefficient of determination $R^{2}$ as well as the sum of square error (SSE). These two measures provide both a measure of variability as well as how close the model is to the experimental data. High and low values for $R^{2}$ and SSE respectively identify goodness-of-fit. The results of fitting the linear stress-strain response between the test data and the values recalculated through coefficients provided $R^{2}$ errors of 0.994 and a SSE close to $10^{-8}$, identifying an adequate fit.

\subsection{Isotropic hardening model formulation}

Once the linear model was described, with a description of yield strength, the isotropic hardening aspect of the material response was addressed.

The parameter $\hat{\varepsilon}$ represents the accumulated plastic strain and governs the isotropic hardening material model's response:

$$
\hat{\varepsilon}=2 \Delta \varepsilon_{\mathrm{p}} N
$$

where $N$ is the cycle number and $\Delta \varepsilon_{\mathrm{p}}$ is a constant.

The evolution of the change in shape of the yield surface can be described through the nonlinear isotropic model by Eq. 4. Eq. 4 is the differential form of what presented in Table 3 for isotropic hardening model. The isotropic hardening parameter is now related to the drag stress, which is a physical parameter that depicts the yield stress behavior. The drag stress 


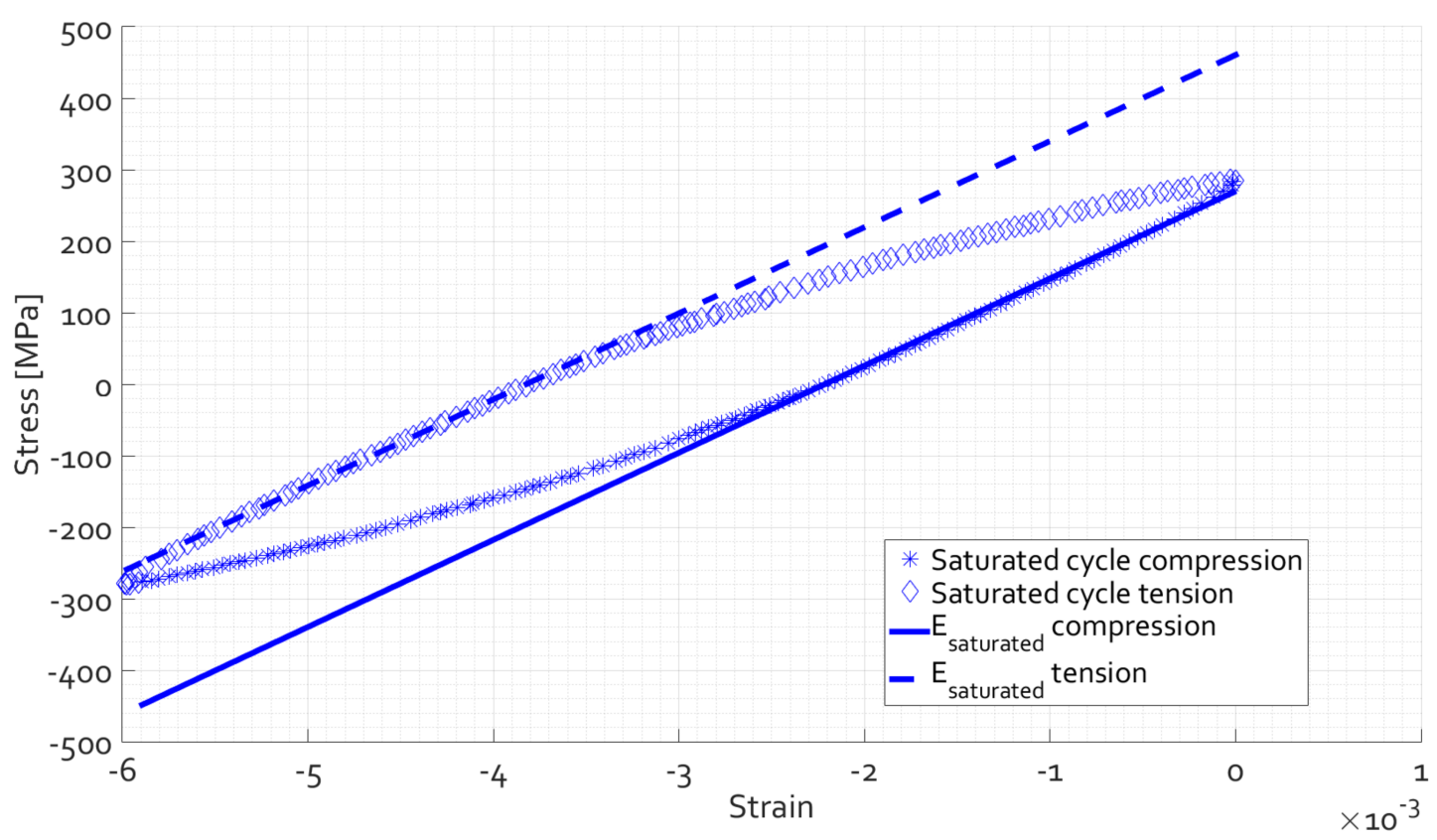

(a)

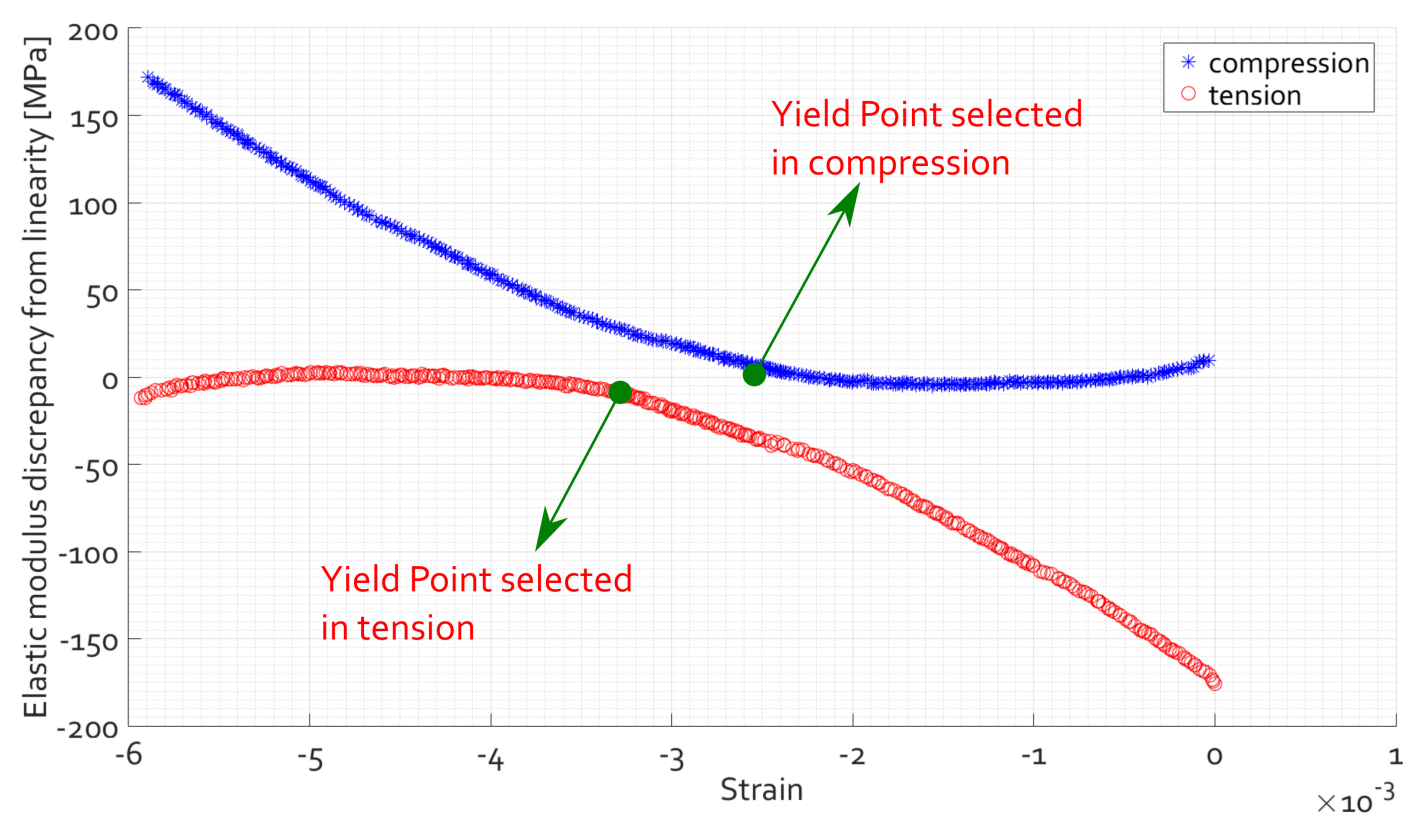

(b)

Figure 8: Example of Young's modulus calculation of the saturated cycle for Specimen Id. 4 subjected to $0.6 \% \Delta \varepsilon$ at $1038^{\circ} \mathrm{C}$. Linear fitting of elastic portion of cycle shown in (a), with a graphical depiction of Eq. 2 (b). Young's modulus in compression was $120 \mathrm{GPa}$, and in tension $122 \mathrm{GPa}$. Mean stress for the given cycle is $3 \mathrm{MPa}$. 
means the difference between the current yield stress and the initial yield stress. Physically, this can be attributed to the interactions among moving dislocations.

$$
\partial \sigma_{\mathrm{D}}(Q)=b\left(\sigma_{\mathrm{D} \infty}-\sigma_{\mathrm{D}}\right) \partial \hat{\varepsilon}
$$

Here, $b$ indicates the speed of stabilization and $\sigma_{\mathrm{D} \infty}$ is the maximum increment of $\sigma_{\mathrm{D}}$ that can have the material saturate. Both parameters are temperature dependent and are found by numerically integrating Eq. 4. The relation that rises from the integration takes an exponential form:

$$
\sigma_{\mathrm{D}}=\sigma_{\mathrm{D} \infty}[1-\exp (-b \hat{\varepsilon})]
$$

$\sigma_{\mathrm{D}}$ parameter was found to grow rapidly and then stabilize to its asymptotic value of $\sigma_{\mathrm{D} \infty}$. This parameter was captured by taking the difference between the maximum stress at the first cycle $\left(\sigma_{\max , 1}\right)$ and that of the stabilized $\left(\sigma_{\max , \mathrm{s}}\right)$.

\subsection{Kinematic hardening model formulation}

The kinematic hardening parameters were evaluated with single stress-strain curves at regular cyclic intervals, with parameters established from specific strain amplitudes. Employing the yield stress determination procedure described in Section 4.2, plastic intervals were isolated for the first and saturated cycles. Once the boundaries were identified, the actual plastic strain stress range (backstress) was identified. The plastic strain range was obtained by subtracting the elastic response from the total range according to:

$$
\Delta \varepsilon_{p}=\Delta \varepsilon-\frac{\Delta \sigma}{E}
$$

The plastic part of the backstress was obtained by subtracting the actual yield value to the stress range i.e. $\Delta \sigma-\sigma_{y}$, after Novak [27]. This approach is exemplified by specimen 3 shown in Fig. 9. The subsequent fitting procedure and follows that employed by others [19, 20, 23, 27]:

$$
\alpha_{i}=\sum_{1}^{\max } \frac{c_{i}}{a_{i}}\left[1-\exp \left(-a_{i} \varepsilon_{p}\right)\right]
$$

These coefficients were optimized using an LM technique to minimize error over all parameters simultaneously. 

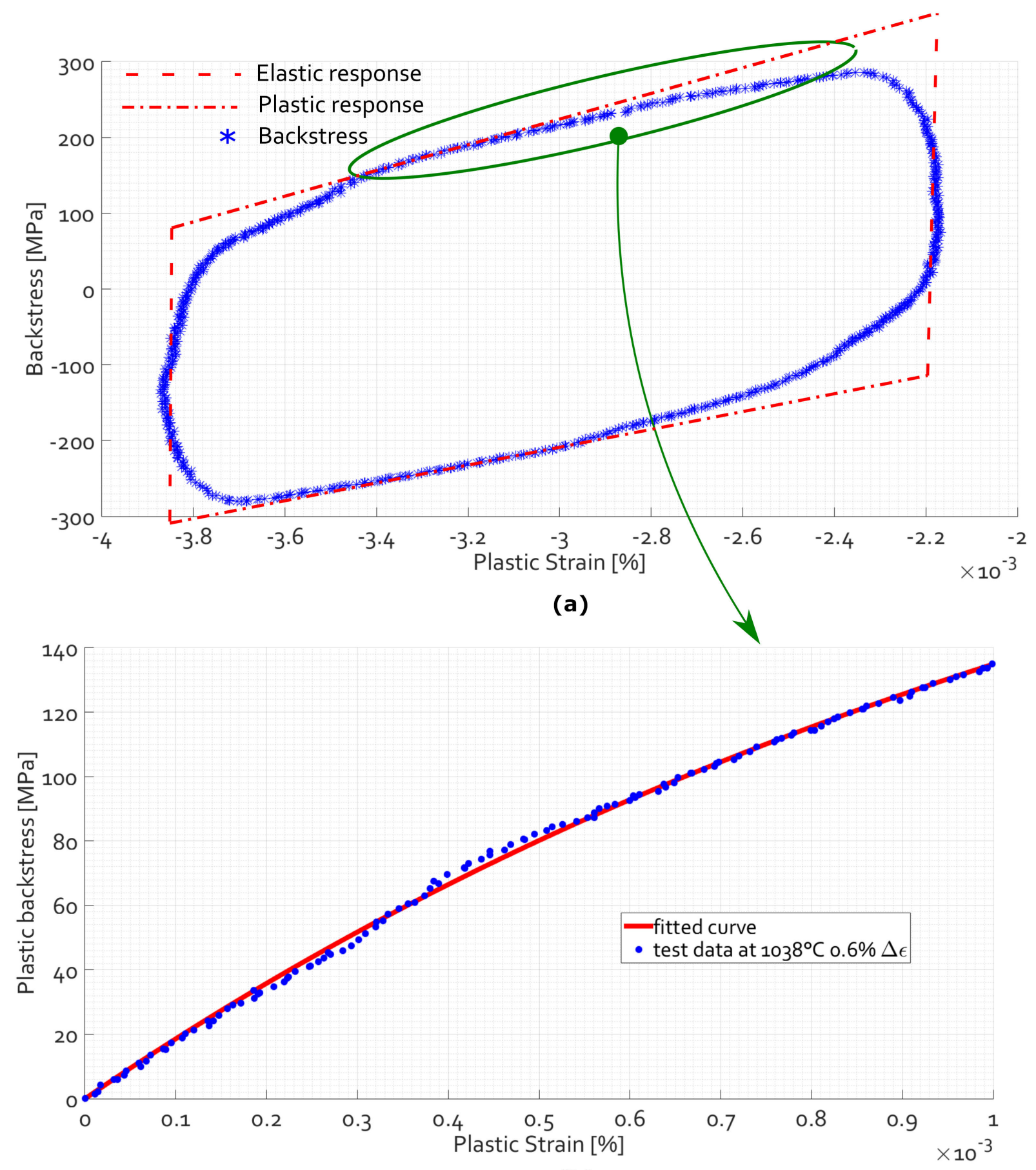

(b)

Figure 9: The stabilized cycle for Specimen Id. 3 at $0.6 \% \Delta \varepsilon$ and $1098^{\circ} \mathrm{C}$ showing the division between elastic and plastic response (a). The fitted plastic response obtained (b). 
Novak and Saad [20] showed in their studies as it is possible to work on curve fitting even with just 1 or 2 pairs of kinematic hardening coefficients but 3 pairs resulted to provide the best compromise between model accuracy and complexity. As already shown in other studies, such as in Novak [27] and Kalnins et al. [29], three pairs of coefficients allow to get the best correlation with experimental data. Fig. 9p shows a typical result resulting from the LM optimization for specimen 3 employing 3 parameters. The average statistical results of the fitting are $R^{2}$ errors of 0.9986 and SSE about 200. Fitting and optimization results for specimens corresponding to $1098^{\circ} \mathrm{C}$ at each strain range are summarized in Table 4 .

Table 4: Overall summary of Lemaitre-Chaboche model parameters at $1098^{\circ} \mathrm{C}$

\begin{tabular}{|c|c|c|c|c|c|c|}
\hline Strain & \multicolumn{4}{|c|}{ Linear parameters } & \multicolumn{2}{|c|}{ Isotropic parameters } \\
\hline$\Delta \varepsilon[\%]$ & & $\mathrm{E}[\mathrm{GPa}]$ & $\sigma_{y}[\mathrm{MPa}]$ & & $\mathrm{Q}[\mathrm{MPa}]$ & $\mathrm{b}[-]$ \\
\hline 0.4 & & 138 & 100 & & 100 & 9.9 \\
\hline 0.6 & & 123 & 138 & & 102.3 & 3.74 \\
\hline 0.8 & & 123 & 140 & & 80 & 1.34 \\
\hline Strain & \multicolumn{6}{|c|}{ Kinematic parameters } \\
\hline$\Delta \varepsilon[\%]$ & $\mathrm{c}_{1}[\mathrm{MPa}]$ & $\mathrm{a}_{1}[-]$ & $\mathrm{c}_{2}[\mathrm{MPa}]$ & $\mathrm{a}_{2}[-]$ & $\mathrm{c}_{3}[\mathrm{MPa}]$ & $\mathrm{a}_{3}[-]$ \\
\hline 0.4 & $1.152 \mathrm{e}+5$ & 2447 & $2.107 \mathrm{e}+5$ & 3348 & $6.457 \mathrm{e}+4$ & 11.54 \\
\hline 0.6 & $6.384 \mathrm{e}+4$ & 455 & $8.099 \mathrm{e}+4$ & 2407 & $6.873 \mathrm{e}+4$ & 459.4 \\
\hline 0.8 & $5.798 \mathrm{e}+4$ & 404 & $7.175 \mathrm{e}+4$ & 2303 & $6.309 \mathrm{e}+4$ & 405.9 \\
\hline
\end{tabular}

\subsection{Model verification}

In order to benchmark the model obtained with parameters described by Table 4, statistical errors $\mathrm{R}^{2}$ and SSE have been evaluated over experimental stress-strain data. Table 5 shows a summary of the resulting verification.

The LC model realized has been found to address both kinematic and isotropic hardening effects in a robust manner. However, it was found that the model does perform better for higher strain ranges. In comparing the model performance for $0.4 \% \Delta \varepsilon$, with 0.6 and $0.8 \%$ $\Delta \varepsilon$, it is evident from the SSE values as per Table 5 that there is one order of magnitude 
Table 5: Selected comparison between experimental and modeled material response for specimens at $1098^{\circ} \mathrm{C}$ using parameters from Table 4

\begin{tabular}{lcc|ccc}
\hline $\begin{array}{l}\text { Specimen } \\
\text { Id. }\end{array}$ & & & \multicolumn{4}{|c}{$\Delta \varepsilon \%$} \\
\hline \multirow{2}{*}{1} & & 0.4 & 0.6 & 0.8 \\
\hline \multirow{2}{*}{3} & 0.8 & $\mathrm{R}^{2}$ & 0.9739 & 0.9785 & 0.9949 \\
& & $\mathrm{SSE}$ & $1.588 \mathrm{e}+6$ & $1.1487 \mathrm{e}+5$ & $2.320 \mathrm{e}+5$ \\
\hline \multirow{2}{*}{5} & 0.6 & $\mathrm{R}^{2}$ & 0.95 & 0.9845 & 0.9898 \\
& & $\mathrm{SSE}$ & $1.5 \mathrm{e}+6$ & $3.9621 \mathrm{e}+5$ & $2.4992 \mathrm{e}+5$ \\
\hline \hline
\end{tabular}

larger error for the lower strain range cases. This has been attributed to the effects of plastic strain accumulation, whereby the combined effects of kinematic and isotropic hardening are difficult to disambiguate, and therefore the model formulation becomes highly dependent on the number of cycles required for saturation at the lower strain ranges. In order to take into account for this, it is possible to tune the $b$ parameter, which represents the rate at which the isotropic hardening model reaches its asymptotic value respect to the accumulated plastic strain.

From this observation, it was found that the parameters are interchangeable between the three different strain amplitudes examined. The data at the lower strain amplitude, $0.4 \% \Delta \varepsilon$, which demonstrate a higher number of cycles before stabilization than higher amplitudes, can be modified by changing the speed of saturation parameter $b$ (Eq. 5). This is particularly advantageous within an implicit FEA application, whereby for small strain ranges it is possible to expedite FEA convergence. Fig. 10 (b) demonstrates the effects of tuning the model by employing a different $b$ parameter.

To further examine the error associated with using parameters determined from one set of strain ranges to describe other conditions, parameters from $0.6 \% \Delta \varepsilon$ were applied to other strain ranges. Fig. 10 (a), (b) and (c) shows the discrepancy between values obtained these parameters and experimentally obtained $0.6 \% \Delta \varepsilon$ as a basis for those compared against those for 0.4 and $0.8 \% \Delta \varepsilon$. This comparison shows that the parameters developed for one strain 
range can be used to extrapolate to higher and lower strain ranges within the same error as it was fitted. This shows that a limited experimental regime could be employed for similar materials to generate a similar model within a reasonable range of accuracy.

It is finally of interest to compare the results with other viscoplastic models applied to the MAR-M-247, specifically with Neu-Seitoglu [28] as developed by Brindley [7]. Focusing on $1038^{\circ} \mathrm{C}$, the $\mathrm{R}^{2}$ result is about 0.9815 , while the normalized SSE is about 765 . The normalized SSE's for the optimized parameters found in this paper are 702,80 and 253 for $\Delta \varepsilon=0.4$, 0.6 and $0.8 \%$ respectively. The optimization procedure for LC parameters provides reliable not require any specific material subroutine to be written. Differently the Neu-Seitoglu model requires a fully three dimensional user material (UMAT) routine to be implemented within the analytical tool.

\section{Conclusion}

In the present work, equiaxed MAR-M-247 has been subjected to low cycle fatigue to higher strain ranges at $1038^{\circ} \mathrm{C}$, a temperature higher than previously reported in the available literature. Failure modes have identified that cracks predominantly initiate at hafnium carbides and propagate on a transgranular basis until intergranular fast fracture. Secondary cracking was observed, which was complicated by oxidation. Stabilization of the cyclic behavior occurred more rapidly with higher strain intervals. Based on the cyclic behavior of the three strain ranges tested $(0.4,0.6$ and $0.8 \% \Delta \varepsilon)$, a Lemaitre-Chaboche constitutive model has been developed, such that it reflects in-service conditions for gas turbine components.

Comparing the results with available models from the literature [7, 27, 30], this LC model has demonstrated to be able to work properly even if used for different strain ranges with respect to the one used for the calibration process. From a finite element analysis standpoint, this demonstrates that Lemaitre-Chaboche parameters may be extrapolated to other strain ranges for a given temperature. The minimum statistical $\mathrm{R}^{2}$ error for the LC model is $97 \%$ at $0.4 \%$ strain range. The maximum SSE is about $6.8 \times 10^{5}$ was found for this range. Strain ranges of 0.6 and $0.8 \% \Delta \varepsilon$ perform better lowering the SSE to $6.03 \times 10^{4}$ and raising the $\mathrm{R}^{2}$ to 0.997 . 


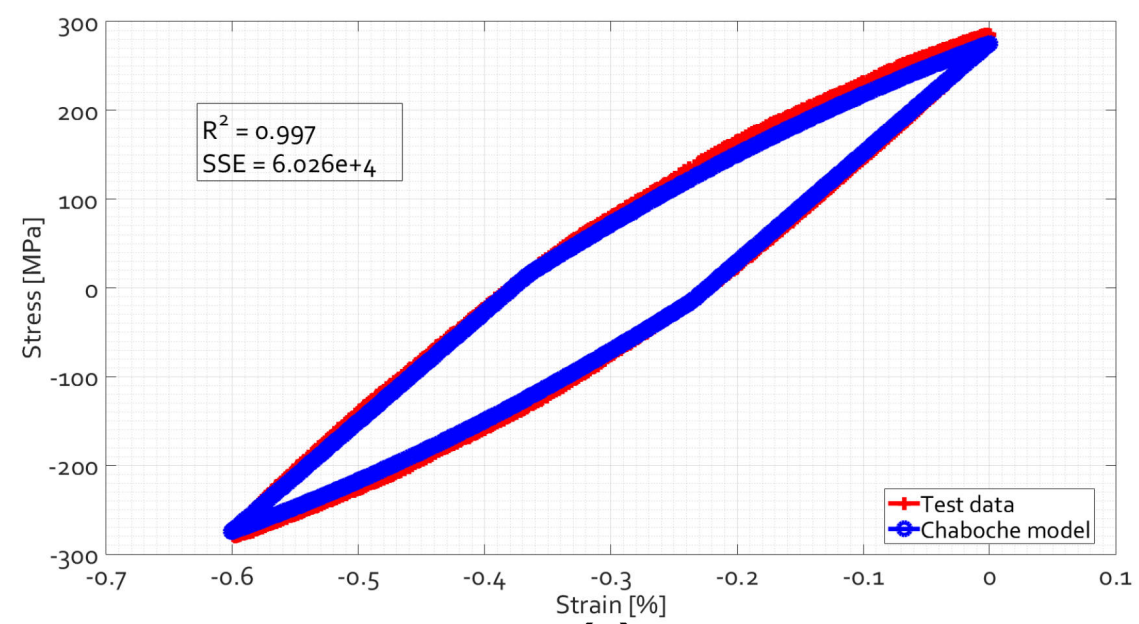

(a)

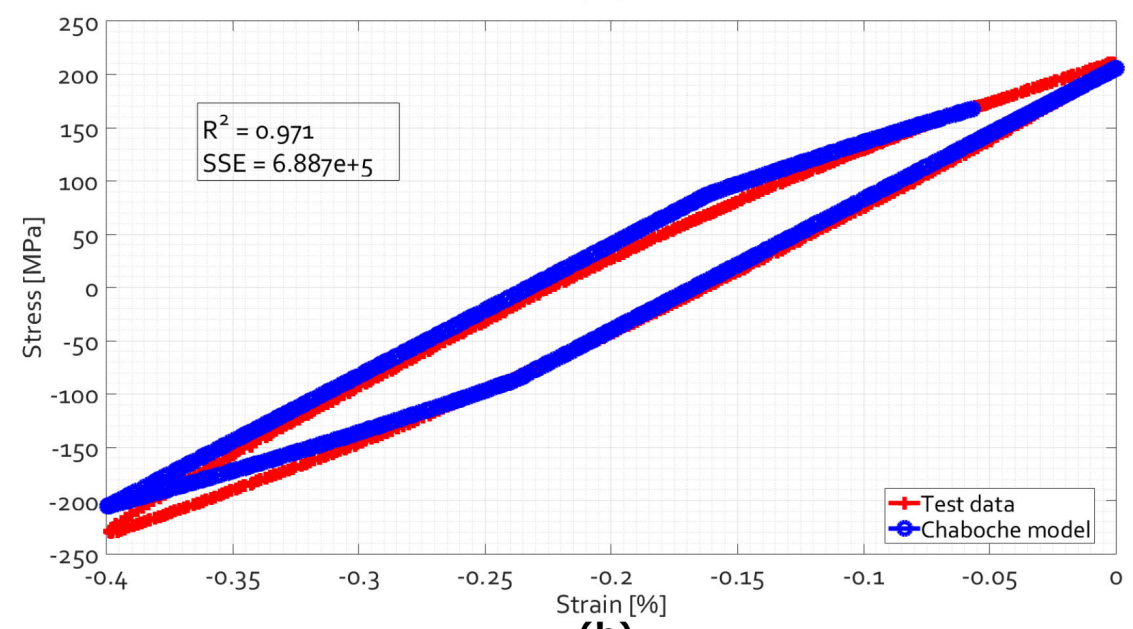

(b)

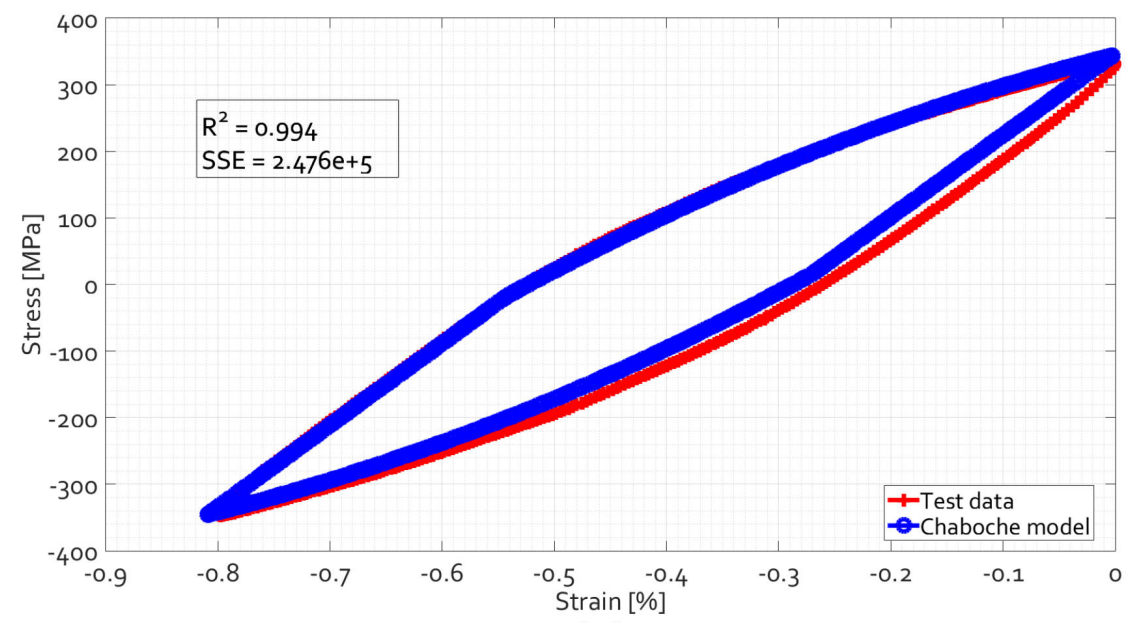

(c)

Figure 10: Results from mathematical LC model application. (a) Parameters from $0.6 \% \Delta \varepsilon$ applied to $0.6 \%$ test data at $1038^{\circ} \mathrm{C}$, Specimen Id. 4. The accuracy is good despite a large SSE value that proofs the capability of shaping the data distribution. (b) Parameters from $0.6 \% \Delta \varepsilon$ applied to $0.4 \%$ test data at $1038^{\circ} \mathrm{C}$, Specimen ID. 5 (c) Parameters from $0.6 \% \Delta \varepsilon$ applied to $0.8 \%$ test data at $1038^{\circ} \mathrm{C}$, Specimen ID. 1. Statistical errors are aligned with previous Fig. (a). This is due to same mechanical and microstructural response of the material at these two strain ranges. 24 
Further work will be to decouple creep response from cyclic behavior in order to establish how much recovery occurs at temperature. However, based on the fractographic observations made here, it appears that oxidation of secondary cracks will complicate this approach. Nevertheless, the LC approach documented here remains a much improved approach than

\section{Acknowledgments}

The authors would like to thank Baker Hughes, a GE Company, for supporting and sponsoring this research. The authors would also like to thank Chris Leonhardt from Metcut, USA, for his experimental support. Further gratitude is extended to to Hubert Matysiak from BHGE for his useful and relevant comments.

\section{References}

[1] P. Bednarz, J. Szwedowicz, Engineering approach for LCF assessment of porous alloys, in: Proceedings of ASME Turbo Expo 2015: Turbine Technical Conference and Exposition GT2015 June 15 19, 2015, Montreal, Canada, Montreal, Canada, 2015, pp.

[2] G. R. Halford, B. M. Steinetz, C. M. Rimnac, Strain-Life Assessment of Grainex Mar-M 247 for NASA Turbine Seal Test Facility, Tech. Rep. April, NASA, USA, Cleveland, Ohio (2004).

[3] G. Maggiani, M. J. Roy, S. Colantoni, P. J. Withers, Improved low cycle fatigue analysis

[4] P. Bednarz, J. Szwedowicz, Crack growth under cyclic loading and plasticity conditions, in: Proceedings of ASME Turbo Expo 2014: Turbine Technical Conference and Exposition GT2014 June 16 20, 2014, Dsseldorf, Germany, Dusseldorf, Germany, 2014, pp. $1-10$. 
[5] S. Pollock, Tresa M and Tin, Nickel-Based Superalloys for Advanced Turbine Engines : Chemistry, Microstructure, and Properties, Journal of Propulsion and Power 22 (2) (2006) 361-374.

[6] R. C. . Reed, The Superalloys., in: The Superalloys. Fundamentals and Applications, 1st Edition, Cambridge University Press, 2006, Ch. 2, p. 390.

[7] K. A. Brindley, Thermomechanical fatigue of MAR-M-247: extension of a unified constitutive and life model to higher temperatures, Master of science, Georgia Institute of Technology (2014).

[8] M. Kaufman, Properties of Cast MAR-M-247 for Turbine Blisk Applications, Tech. rep., General Electric, USA (1982).

[9] A. Martín-meizoso, Thermomechanical fatigue behaviour and life prediction of MARM-247 nickel based superalloy, Tech. rep., CEIT (2011).

[10] D. J. Morrison, J. C. Moosbrugger, Effects of grain size on cyclic plasticity and fatigue crack initiation in nickel, Elsevier International Journal of Fatigue 19 (1997) 51-59. doi.org/10.1016/s0142-1123(97)00034-0.

[11] H. Sehitoglu, D. Boismier, Thermo-mechanical fatigue of mar-m247. part 2. life prediction", Journal of Engineering Materials and Technology, Transactions of the ASME 112 (1) (1990) 80-89.

[12] R. J. Kashinga, L .G. Zhao, V. V. Silberschmidt, F. Farukh, N. C. Barnard, M. T. Whittaker, D. Proprentner, B. Shollock and G. McColvin, Low cycle fatigue of a directionally solidified nickel-based superalloy: Testing, characterisation and modelling, Elsevier Materials Science and Engineering:A 708 (2017) 503-513 doi •org/10.1016/ j.msea.2017.10.024.

[13] M. Maldini, H. Harada, Y. Koizumi, T. Kobayashi, V. Lupinc, Tertiary creep behaviour of a new single crystal superalloy at 900 C, Scripta Materialia 43 (7) (2000) 637-644. doi:10.1016/S1359-6462(00)00473-5. 
[14] B. Piearcey, B. Terkelsen, The effect of unidirectional solidification on the properties of cast nickel-base superalloys, AIME MET SOC TRANS 239 (8) (1967) 1143-1150.

[15] I. Sulak, K. Orbtlik, Effect of tensile dwell on high-temperature low-cycle fatigue and fracture behaviour of cast superalloy MAR-M247 (2017) 92-100.

[16] R. Baldan, C. A. Nunes, M. J. R. Barboza, A. M. S. Costa, R. Bogado, G. C. Coelho, Tensile properties of MAR-M-247 superalloy, International conference on advanced materials.

[17] A. van den Beukel, Theory of the effect of dynamic strain aging on mechanical properties, in: Physical Status Solidi, 30, Delft, The Netherlands, 1975, pp. 197-206.

[18] A. P. Gordon, T. Bouchenot, A reduced order constitutive modeling approach for a material subjected to combined cycle fatigue, Turbo Expo: Power for Land, Sea, and Air (2018) doi.org/10.1115/GT2018-76903.

[19] T. Harth, Identification of Material Parameters for Inelastic Constitutive Models Using Stochastic Methods, Wiley-VCH Verlag GmbH \& Co. 429 (2) (2007) 409-429.

[20] A. A. Saad, Cyclic Plasticity and Creep of Power Plants Materials, Doctor of philosophy thesis, University of Nottingham (2012).

[21] J. L. Chaboche, G. Rousselier, On the Plastic and Viscoplastic Constitutive EquationsPart I: Rules Developed With Internal Variable Concept, ASME Journal of Pressure Vessel Technology 105 (2) (1983) 153-158. $10.1115 / 1.3264257$.

[22] J. L. Chaboche, Unified Cyclic Viscoplastic Constitutive Equations: Development, Capabilities, and Thermodynamic Framework, Elsevier Unified Constitutive Laws of Plastic Deformation (1996) 1-68. 10.1016/b978-012425970-6/50002-3.

[23] J. L. Chaboche, A review of some plasticity and viscoplasticity constitutive theories, Elsevier International Journal of Plasticity 24 (2008) 1642-1693. doi:10.1016/j. ijplas.2008.03.009. 
[24] J. L. Chaboche,D. Nouailhas, D. Pacou, P. Paulmier, Modeling of the cyclic response and ratchetting effects on Inconel-718 alloy, European Journal of Mechanics, A/Solids 10 (1991) 101-121.

[25] J. Tong, Z.L. Zhan, B. Vermeulen, Modelling of cyclic plasticity and viscoplasticity of a nickel-based alloy using Chaboche constitutive equations, International Journal of Fatigue 26 (8) (2004) 829-837 doi.org/10.1016/j.ijfatigue.2004.01.002.

[26] Z.L. Zhan and J. Tong, A study of cyclic plasticity and viscoplasticity in a new nickel-based superalloy using unified constitutive equations. Part I: Evaluation and determination of material parameters, Mechanics of Materials 39 (1) (2007) 64-72 doi.org/10.1016/j.mechmat.2006.01.005.

[27] J. S. Novak, Parameter estimation of cyclic plasticity models and strain-based fatigue curves in numerical analysis of mechanical components under thermal loads, Doctoral thesis, University of Udine (2016).

[28] R.W.Neu, H. Sehitoglu, Thermomechanical Fatigue, Oxidation, and Creep: Part II. Life Prediction, Metallurgical Transactions A 20 (September) (1989) 9.

[29] A. Kalnins, Arturs; Rudolph, Jurgen; Willuweit, Using the Nonlinear Kinematic Hardening Material Model of Chaboche for Elastic Plastic Ratcheting Analysis, Journal of Pressure Vessel Technology 137 (June 2015) (2015) 10. doi:10.1115/1.4028659.

[30] F. Irmak, A. P. Gordon, A framework for life prediction of 2.25Cr-1Mo under creep and thermomechanical fatigue, in: Proceedings of ASME Turbo Expo 2018: Turbomachinery Technical Conference and Exposition GT2018 June 11 15, 2018, Oslo, Norway, Oslo, Norway, 2018, pp. 1-11. 